\title{
Throwing the baby out with the bathwater: does laurel forest restoration remove a critical winter food supply for the critically endangered Azores bullfinch?
}

\author{
Ricardo S. Ceia • Hugo L. Sampaio - Sandra H. Parejo • \\ Ruben H. Heleno • Maria L. Arosa • Jaime A. Ramos • \\ Geoff M. Hilton
}

Received: 15 March 2010/Accepted: 19 May 2010/Published online: 5 June 2010

(C) Springer Science+Business Media B.V. 2010

\begin{abstract}
The invasive Clethra arborea has a dualrole in the diet of the Azores bullfinch, a critically endangered bird species endemic to the island of São Miguel (Azores, Portugal). This is a crucial winter food resource but it lowers the availability of native laurel forest species that compose most of the bird's diet throughout the year. The removal of this and other
\end{abstract}

R. S. Ceia $(\bowtie) \cdot$ H. L. Sampaio · S. H. Parejo Portuguese Society for the Study of Birds, Avenida da Liberdade, $105-2{ }^{\circ}$ E, $1250-140$ Lisbon, Portugal e-mail: ricardoceia@gmail.com

\section{R. H. Heleno} Institut Mediterrani d'Estudis Avançats (CSIC-UIB), 07190 Esporles, Mallorca, Balearic Islands, Spain

\section{L. Arosa - J. A. Ramos}

Institute of Marine Research (IMAR/CMA), Department of Life Sciences, University of Coimbra, P.O. Box 3046, 3001-401 Coimbra, Portugal

\section{G. M. Hilton}

Royal Society for the Protection of Birds (RSPB), The Lodge, Sandy, Beds SG19 2DL, United Kingdom

Present Address:

M. L. Arosa

Centre for Functional Ecology, Department of Life

Sciences, University of Coimbra, P.O. Box 3046,

3001-401 Coimbra, Portugal

Present Address:

G. M. Hilton

Wildfowl \& Wetlands Trust, Slimbridge,

Glos GL2 7BT, UK invasive alien species is part of current laurel forest habitat restoration programmes, disregarding the impact on the Azores bullfinch population. In order to evaluate the first responses of the Azores bullfinch to habitat restoration, we studied bird diet, foraging behaviour, food availability and habitat occupancy in managed (without $C$. arborea) and control areas. Significant increases in the availability of native food resources in managed areas were noticeable in the diet, particularly the intake of Ilex perado ssp. azorica and Prunus lusitanica ssp. azorica flower buds. In most of the studied months birds heavily used and foraged in managed over control areas. The one exception was in December, when a resource-gap occurred in managed areas, which may be overcome in the short-term due to re-establishment of native plants following removal of invasive aliens.

Keywords Azores - Clethra arborea . Endangered species - Habitat restoration . Laurel forest · Pyrrhula murina

\section{Introduction}

Invasive alien plants constitute an important threat to many ecosystems worldwide and have been described as the second main threat to biodiversity, following habitat loss (Vitousek et al. 1997). Clearance of invasive plants and restoration of native vegetation is nowadays a major conservation activity, 
covering large areas at substantial economic cost (Vander Zanden et al. 2006 and references therein; Forup et al. 2008). Such management is motivated by the wish to conserve native flora and fauna and the important ecosystem functions that they support (Kremen and Hall 2005). However, there may be a time-lag between removal of the dominant invasive plants and the recovery of a fully functional native vegetation community (Young et al. 2001). During this hiatus, various risks might increase, such as soil erosion (Dobson et al. 1997). Less well studied is the shift from native to alien food resources by native consumers, and the consequences of restoration activities on such consumers. The problem here is that removal of the alien plants could cause a resource-gap during the period prior to full re-establishment of native plants (Young et al. 2001). Therefore, conservationists can potentially be faced with the conflicting problems of restoring the native flora from the invasion or maintaining an important (but alien) resource for native consumer species of conservation concern (Ramos 1996a; Van Riel et al. 2000; D'Antonio and Meyerson 2002; Rodriguez 2006).

Increasing environmental degradation has meant that the restoration of threatened species is becoming ever more important (Bowles and Whelan 1994). Birds are unquestionably a privileged group in this regard: a number of conservation programmes have the aim of restoring threatened bird species through alien plant control (Genovesi 2005; Butchart et al. 2006). The Azores bullfinch or Priolo (Pyrrhula murina) is one such species. It is critically endangered (BirdLife International 2008), and the estimated population of 1,608 individuals (Monticelli et al. 2010) is restricted to about 6,000 ha in the east of the island of São Miguel, Azores, in the Special Protection Area of Pico da Vara/Ribeira do Guilherme, of which less than $30 \%$ is currently occupied by native vegetation (Ramos 1996a; Ceia 2008). Within this area, native forest was largely cleared in the 1960 s for afforestation with Cryptomeria japonica (Japanese red cedar), and more recently the remaining native forest has been heavily invaded by aggressive alien plants, primarily Pittosporum undulatum (Australian cheesewood), Clethra arborea (Lilly-of-the-valley tree) and Hedychium gardneranum (Kahili ginger) (Silva and Smith 2004). These plants have been gradually replacing the biodiversity rich laurel forest (Heleno et al. 2009) upon which the Azores bullfinch is highly dependent and with the remarkable exception of $C$. arborea they do not provide alternative food resources for the birds (Ramos 1995). Ramos (1995) studied the diet of the Azores bullfinch between 1991 and 1993 and showed that, like the European bullfinch (Pyrrhula pyrrhula), Azores bullfinches mainly take seeds of herbaceous plants and invertebrates in late spring and summer, seeds from fleshy fruits in autumn and winter, tree seeds in winter and flower buds in early-spring. In addition, the Azores bullfinch feeds also on fern sporangia and fronds from winter to early-summer (Ramos 1994, 1995; Arosa 2008). Most food items taken by the Azores bullfinch are native laurel forest species, but the introduced $C$. arborea has now assumed an important role in its diet (Ramos 1995). From late spring to late autumn most native plants are seeding (Schäffer 2002) and there appears to be plenty of available food for the Azores bullfinch, however, the period from December to April (winter and earlyspring) is critical in terms of food supply (Ramos 1995). Earlier work indicates that stocks of native fleshy fruits, seeds and fern sporangia are largely depleted by January-February, while flower buds of the endemic Ilex perado ssp. azorica (holly) only become available from March to April onwards (Ramos 1995), as probably do the flower buds of Prunus lusitanica ssp. azorica (Portuguese laurel cherry), a potentially important food resource not evaluated in previous studies. Conversely, fruits of the invasive $C$. arborea are available throughout the winter (Ramos 1996b). However, this species grows taller and is present in higher densities than native species (Silva 2001), therefore it may lower the production of native food sources taken at other times of the year, especially flower buds of I. perado ssp. azorica in March and April (Ramos 1996a; Ceia and Silva 2008; Heleno et al. 2009). Given the high conservation interest of the Azores bullfinch, an ambitious habitat restoration project started in October 2003 aiming to eradicate invasive alien plants from 300 ha in the core of its range. However, in the shortterm the removal of $C$. arborea potentially removes a major winter food source for the Azores bullfinch, and it is therefore crucial to understand fully the impact of alien plant removal on its feeding ecology.

This study examines the first responses of the Azores bullfinch to habitat restoration, comparing bird diet and foraging behaviour, food availability and habitat occupancy between managed and control 
areas. We expect that habitat management will increase native food availability leading to an increased foraging by Azores bullfinches in managed areas (Ramos 1996a; Newton 1998). In addition we provide up to date information on monthly variation in the food items which compose the diet of the Azores bullfinch (including data from a large area in the core of the Azores bullfinch distribution only recently made accessible by the ongoing conservation actions).

\section{Methods}

This study was carried out from August 2006 to July 2007 in São Miguel, the only one of the nine islands of the Azores archipelago (Portugal) where the Azores bullfinch occurs. Located in the middle of the North Atlantic Ocean, the Azores are characterized by a temperate oceanic climate with moderate rainfall spread evenly throughout the year, high relative humidity, and small temperature range (Silva and Smith 2004).

Our study area spread over 2000 ha in Serra da Tronqueira, in the eastern part of São Miguel $\left(37^{\circ} 47^{\prime} \mathrm{N}, 25^{\circ} 13^{\prime} \mathrm{W}\right)$, and ranged from 320 to $890 \mathrm{~m}$ a.s.l. (Fig. 1). Serra da Tronqueira is a mountainous district with steep densely vegetated ground (Ramos 1995; Silva 2001; Gil 2005). Most native vegetation in the east of São Miguel has been cleared for pastures, afforested with $C$. japonica or taken over almost completely by $P$. undulatum on slopes along streams up to $500 \mathrm{~m}$ and by $H$. gardneranum on disturbed ground and streams (Ramos 1996a). C. arborea is scattered widely through the whole remnants of native forest (Ramos 1996a; Silva 2001). More lightly invaded patches of native forest remain only above $500 \mathrm{~m}$ in the cloud zone (Silva 2001). Taxonomic classification of plant species throughout this work follows Silva et al. (2005).

\section{Habitat management}

Between 2003 and 2008 a conservation project was undertaken in the study area, involving the clearance of invasive alien plant species among other concrete habitat management actions to improve its quality for the Azores bullfinch. Consequently, C. arborea and $H$. gardneranum were removed from about 50 ha with the herbicide Ally ${ }^{\circledR}$ (metsulfuron methyl 20\% $6 \mathrm{~g} / \mathrm{L}$ ) during spring and summer of 2005, both along tracks and within the invaded native forest. These managed areas where alien plant removal occurred, and thus without $C$. arborea, are hereafter referred as cleared areas, whilst the non-managed control areas are referred as non-cleared areas.

\section{Bird diet}

Existing trails (total length $=22 \mathrm{~km}$ ) through the cleared and non-cleared areas (Fig. 1) were walked in
Fig. 1 Map of Serra da Tronqueira in the eastern part of the island of São Miguel, Azores (Portugal). Transects performed to evaluate the habitat use are represented with letters from $A$ to $H$

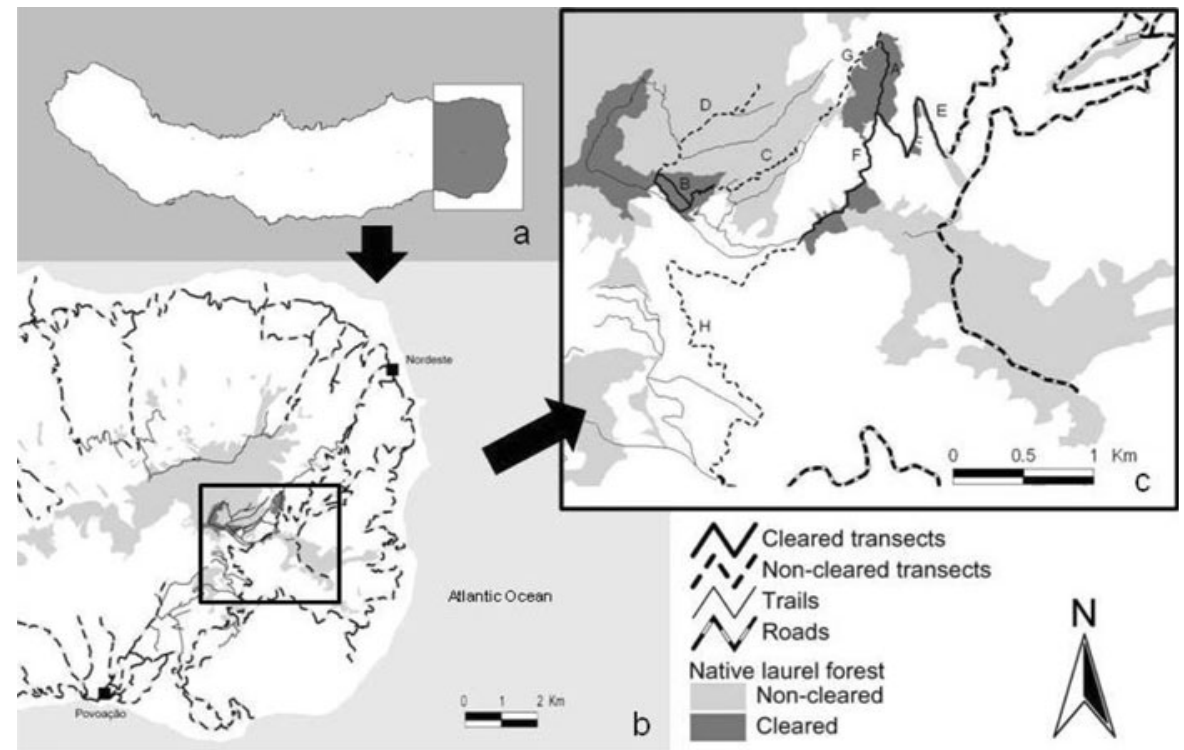


rotation by five observers (H.L.S., M.L.A., R.H.H., R.S.C. and S.H.P.), every other week from August to July, in order to observe foraging birds. When a bird was detected, the observers followed it using binoculars and recorded feeding behaviour. The rule: one bird, one food $=$ one record (Newton 1964) was adopted, and only the first item taken by each focal bird was used to evaluate monthly diet. The independence of records was safeguarded by moving away from previous feeding birds and by the sighting of different colour-ringed birds. Between November and May (the period during which $C$. arborea seeds were consumed) feeding records from cleared and non-cleared areas were separated, in order to evaluate which foods might replace $C$. arborea in areas where this species was removed.

\section{Food availability}

40 plots were sampled in October and re-sampled in March, to evaluate food availability for Azores bullfinches in autumn and early-spring respectively. All the plots were in native laurel forest (20 in cleared areas and 20 in non-cleared areas). We walked all possible trails within the forest core and spread plots over the study area, so that they were at least $50 \mathrm{~m}$ apart. Plots were $30 \mathrm{~m} \times 2 \mathrm{~m}$, and we used a centrally placed $30 \mathrm{~m}$ linear transect for sampling. The number of seeds, fruits, flower buds, flower heads and fertile fern fronds of species known to be taken by the Azores bullfinch were counted within one meter either side of the transect line.

Two altitudinal ranges were selected to sample three important food items for Azores bullfinch's diet (C. arborea seeds; I. perado ssp. azorica and $P$. lusitanica ssp. azorica flower buds): low-altitude (500-650 m) and high-altitude $(650-800 \mathrm{~m})$. To measure monthly abundance of $C$. arborea seeds, 40 individual trees were selected at random in noncleared areas stratified by altitude $(n=20$ at each altitude). The number of remaining fruits was counted monthly, from November until May, on a marked branch with fruits within reach.

Ilex perado ssp. azorica and P. lusitanica ssp. azorica were studied to compare flower bud abundance and provide a measure of their availability in spring. In early March, 48 and 42 randomly selected individuals of $I$. perado ssp. azorica and P. lusitanica ssp. azorica, respectively, were marked within cleared and non-cleared areas and stratified by altitude (I. perado ssp. azorica: $n=12$ for cleared and noncleared areas at each altitude; $P$. lusitanica ssp. azorica: $n=13$ for non-cleared areas at high-altitude, $n=15$ for non-cleared areas at low-altitude, $n=10$ for cleared areas at high-altitude, $n=4$ for cleared areas at low-altitude). Only individuals developing flower buds were selected. The total number of flower buds with a prominent stalk on a marked branch was counted on each individual every other week from March until June.

\section{Habitat use}

In order to evaluate habitat use by Azores bullfinches during the period of potential food shortage after the removal of alien species, edge habitats in the vicinity of native forest patches ( $\mathrm{road}$ and $C$. japonica plantation edges) was also studied together with the main cleared and non-cleared areas. Hence, four habitat categories were defined: (1) native laurel forest cleared of alien plants (cleared native), (2) native laurel forest not cleared of aliens (non-cleared native), (3) forest edge cleared of aliens (cleared edges) and (4) forest edge not cleared of aliens (noncleared edges). Two transects were chosen within each habitat category, totalling eight transects (Fig. 1), and walked at a slow, constant pace early in the morning under good weather conditions three times a month from November to May $(n=168$ transects completed). In order to deal with possible bias in bird's activity, transects were walked from opposite ends on alternate weeks. Some bias might arise from autocorrelation, however additional transects were not possible due to terrain restrictions. All the Azores bullfinches heard or seen were recorded.

As a consequence of $C$. arborea removal, Azores bullfinches may take longer to find food in cleared areas. Alternatively, depending on the scale of individual movements, birds may continue to feed mainly on $C$. arborea fruits, by feeding mainly in non-cleared areas, such that sightings in cleared areas would largely be of birds engaged in non-feeding activities. To assess whether Azores bullfinches spent more time foraging than in other activities in cleared areas, we actively searched for feeding Azores bullfinches in the four habitat categories defined above, by slowly walking all available trails (Fig. 1), from November to May. Whenever an individual was 
observed, behavioural time-budgets were recorded into a speech recorder. If a flock was detected, a randomly chosen bird was followed. Two different behavioural classes were used: feeding (time pecking and in-between continuous pecking) and non-feeding (time exhibiting any other behaviour e.g. preening, calling, flying or perching). Azores bullfinches were searched for over the same time interval in all habitat categories at different times of day and over a range of altitudes, from 320 to $890 \mathrm{~m}$, covering all the available trails. Only birds that were observed for at least $1 \mathrm{~min}$ were used in the analysis. Records are presented as the proportion of time the birds spent feeding in each habitat category.

\section{Statistical analyses}

Abundance of potential food items comprised two elements: the frequency of occurrence on a plot (number of positive records), and the count of positive records, and there was a high proportion of zeros in the data for almost all species. Zero-inflated Poisson (zinp) regression (using software $\mathrm{R}$ version 2.9.2, zeroinfl procedure; R Development Core Team 2009) was therefore used to test for differences in abundances of food resources between cleared and non-cleared areas in October and March. The response variable was the count of the resource and the explanatory variable was 'habitat' (cleared or non-cleared). Units of observation were the count from an individual transect. A Poisson structure was assumed for the count data model, and a binomial structure for the zero-inflation model. Minimum adequate models were developed by stepwise deletion of least-significant variables until a model containing only significant explanatory variables remained. Significant values on the count data model indicate that where the species is present, there is a significant impact of habitat on its abundance. Significant values on the zero-inflated model indicate that there is a significant effect of habitat on the probability of the species being present. In some months, some species were absent from one of the two habitats, and in these cases it is not statistically possible to separate frequency of occurrence from abundance where present. In these instances we used simple Mann-Whitney $U$-Tests to test for an overall difference in abundance between habitats.

Linear and quadratic regressions (using software STATISTICA version 7.0; StatSoft 2004) were fitted to the decline of flower buds of I. perado ssp. azorica and $P$. lusitanica ssp. azorica trees along the season in both cleared and non-cleared areas.

To examine variation in the distribution of Azores bullfinch over the course of November-May, we used a Generalized Linear Mixed Model (GLMM) (using software R version 2.9.2, lmer procedure; R Development Core Team 2009). The response variable was the count of birds per transect, standardised by transect length (in effect, birds per $\mathrm{km}$ ), and converted to an integer, assuming a quasipoisson distribution and log link-function. Transect was declared as a random intercept. Generalized Estimating Equations that modelled the potential temporal autocorrelation within transects sampled on successive occasions did not converge, and so were not used, and temporal autocorrelation was not modelled. We examined habitat category, month, and the interaction between them as explanatory factors. Initial plotting of the data indicated that there was little difference in counts between the 'cleared edge' and 'non-cleared edge' habitats, so these two habitat categories were merged to give a single factor-level 'edge', while 'cleared native' and 'non-cleared native' appeared to differ and were treated separately. Month was a seven-level factor (November to May inclusive).

Data on the proportion of time spent feeding by each focal bird in each habitat and treatment was arcsine transformed and compared using a twoway ANOVA (using software STATISTICA version 7.0; StatSoft 2004) and results are presented as mean \pm standard deviation.

\section{Results}

Bird diet

In total 1,740 feeding records were obtained during this study, which are summarized in Table 1 . In October, foraging birds in cleared and non-cleared areas relied mostly on fleshy fruit seeds, particularly Leycesteria formosa. Between November and February, birds from non-cleared areas relied predominantly on seeds of $C$. arborea, whereas those from cleared areas relied on sporangia of the native ferns Woodwardia radicans and Culcita macrocarpa (Table 1). The diet in March and April was dominated by flower buds in both areas. However, in 
cleared areas flower buds of I. perado ssp. azorica already formed over $20 \%$ of feeding records by January, whereas in non-cleared areas the birds did not feed substantially on I. perado ssp. azorica until March (Table 1). As predicted, flower buds of $P$. lusitanica ssp. azorica were also important in the diet in non-cleared areas, because this species was naturally more common in those areas (not as a result of management activities). In May, fern fronds were the most frequently consumed item in cleared areas, whereas in non-cleared areas, seeds of the herbaceous Persicaria capitata were taken. Seeds of herbaceous plants and fleshy fruits assumed an important role in the diet from June to August and in September, respectively.

\section{Food availability}

Habitat management caused immediate, profound effects on the availability of the removed invasive C. arborea. Indirectly, and most probably due to a light increase, the availability of native food sources was also affected. In October of 2006, ca. 18 months after alien plant removal, there were significantly more seeds of fleshy fruit plants (Rubus ulmifolius: $Z=3.39$, $p<0.001 ; L$. formosa: $Z=2.56, p=0.011$; Table 2) and sori of $W$. radicans $(Z=5.38, p<0.001$; Table 2$)$ in cleared areas than in non-cleared areas. On the other hand, C. macrocarpa was significantly less abundant in cleared areas than in non-cleared areas (Table 2, $t_{38}=4.68, p<0.001$ ), as a side effect of habitat management. In October, seeds of herbaceous plants were present only in cleared areas (Table 2) and these were taken by Azores bullfinch until November (Table 1). In March, there was a significantly higher abundance of $I$. perado ssp. azorica flower buds in cleared areas than in non-cleared areas $(Z=2.62$, $p=0.009$; Table 2). Flower buds of $P$. lusitanica ssp. azorica were noted only in non-cleared areas (Table 2), although this result was an artefact resulting from the fact that $P$. lusitanica ssp. azorica trees were naturally more abundant in those areas than in the 50 ha area from which aliens were removed. $C$. arborea and $H$. gardneranum were not present in cleared areas as they were removed during habitat management (Table 2).

From the $C$. arborea fruits marked in November, $36.45 \pm 21.79 \%, \quad 30.40 \pm 17.84 \%$ and $21.27 \pm$
$15.07 \%$ (mean $\pm \mathrm{SD}$ ) were still available in March, April and May, respectively.

There was no major difference in the temporal availability of $I$. perado ssp. azorica and $P$. lusitanica ssp. azorica between cleared and non-cleared areas (Fig. 2). The abundance of I. perado ssp. azorica flower buds peaked in early March (or possibly earlier, before the beginning of the study), whereas the abundance of $P$. lusitanica ssp. azorica flower buds peaked in April, in both cleared and non-cleared areas.

\section{Habitat use}

The 'transect' random effect was weak (variance parameter estimate $=0.22, \quad \mathrm{SD}=0.47$ ) but was retained since it clearly represents the structure of the data. A model containing only habitat category as explanatory variable was significantly better than a null model (with random effect only) ( $\mathrm{R}$ version 2.9.2, ANOVA procedure, Chi-sq $=16.1, d f=2$, $p<0.001$; R Development Core Team 2009). The addition of month and the habitat type $\times$ month interaction significantly improved the model further (Chi-sq $=69.5$, df $=18, p<0.001)$. This indicates that there are differences in Azores bullfinch abundance between habitat categories and in the seasonal pattern of use of the habitat categories. Inspection of Fig. 3 indicates that cleared native forest generally had higher abundance of Azores bullfinches, while edges had low abundance, and non-cleared native forest intermediate abundance. There was no substantial seasonal variation in abundance in edge habitats, but in cleared native there was a general tendency for abundance to increase between November and May, while in non-cleared native there was a sharp peak in abundance in December, and no other major seasonal variation.

The proportion of time dedicated to feeding varied between edge and forest $\left(F_{1,183}=9.47, p=0.002\right.$; Fig. 4) but not between cleared and non-cleared areas $\left(F_{1,183}=3.38, p=0.068\right)$, with the habitat $\mathrm{x}$ treatment interaction also being non-significant $\left(F_{1,183}=0.22, p=0.641\right)$. The proportion of time spent feeding was higher in cleared habitats (cleared areas: $0.80 \pm 0.26$ and $0.62 \pm 0.32$; non-cleared areas: $0.69 \pm 0.30$ and $0.55 \pm 0.33$, respectively for native forest core and forest edges; Fig. 4). 


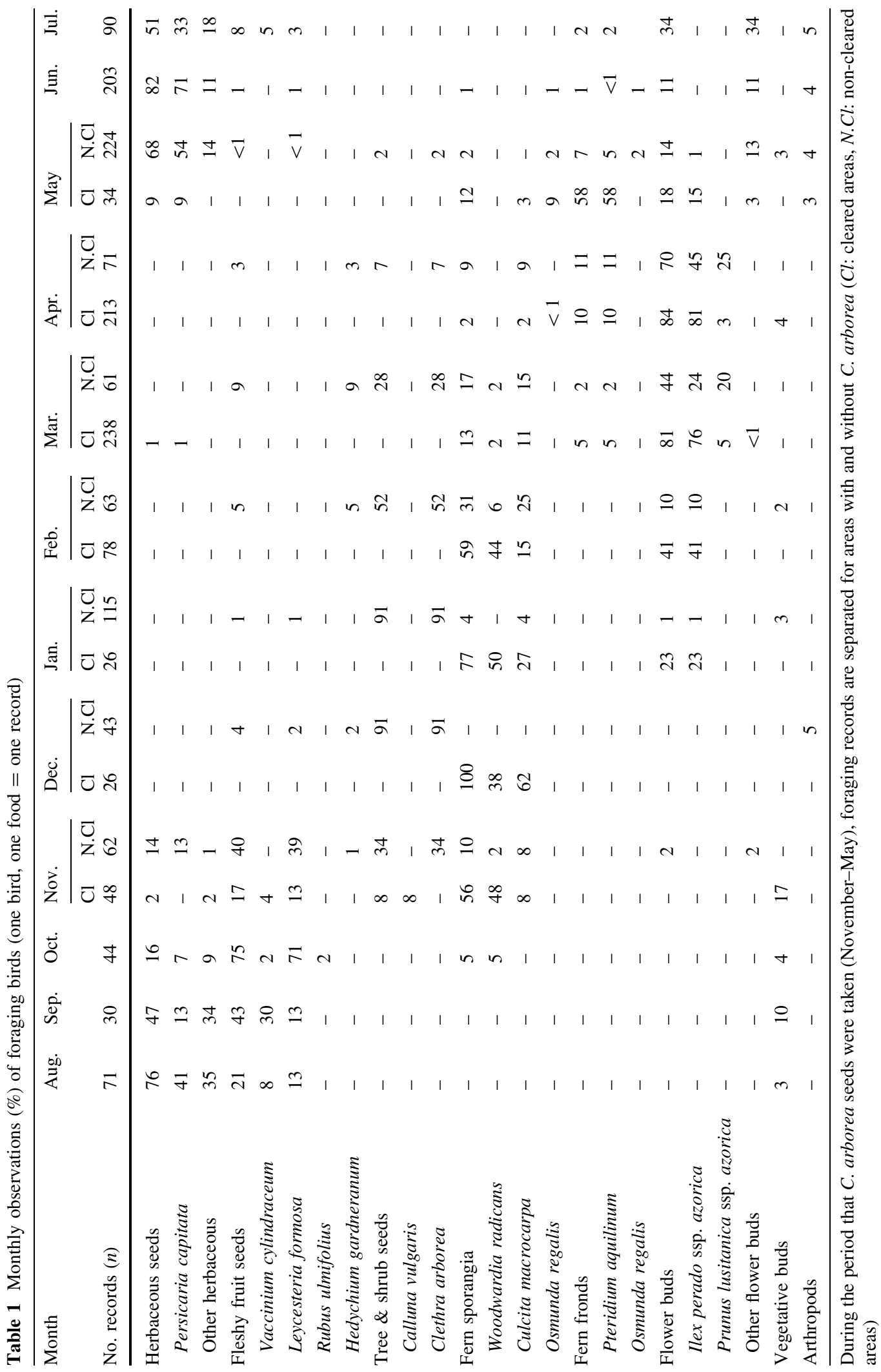




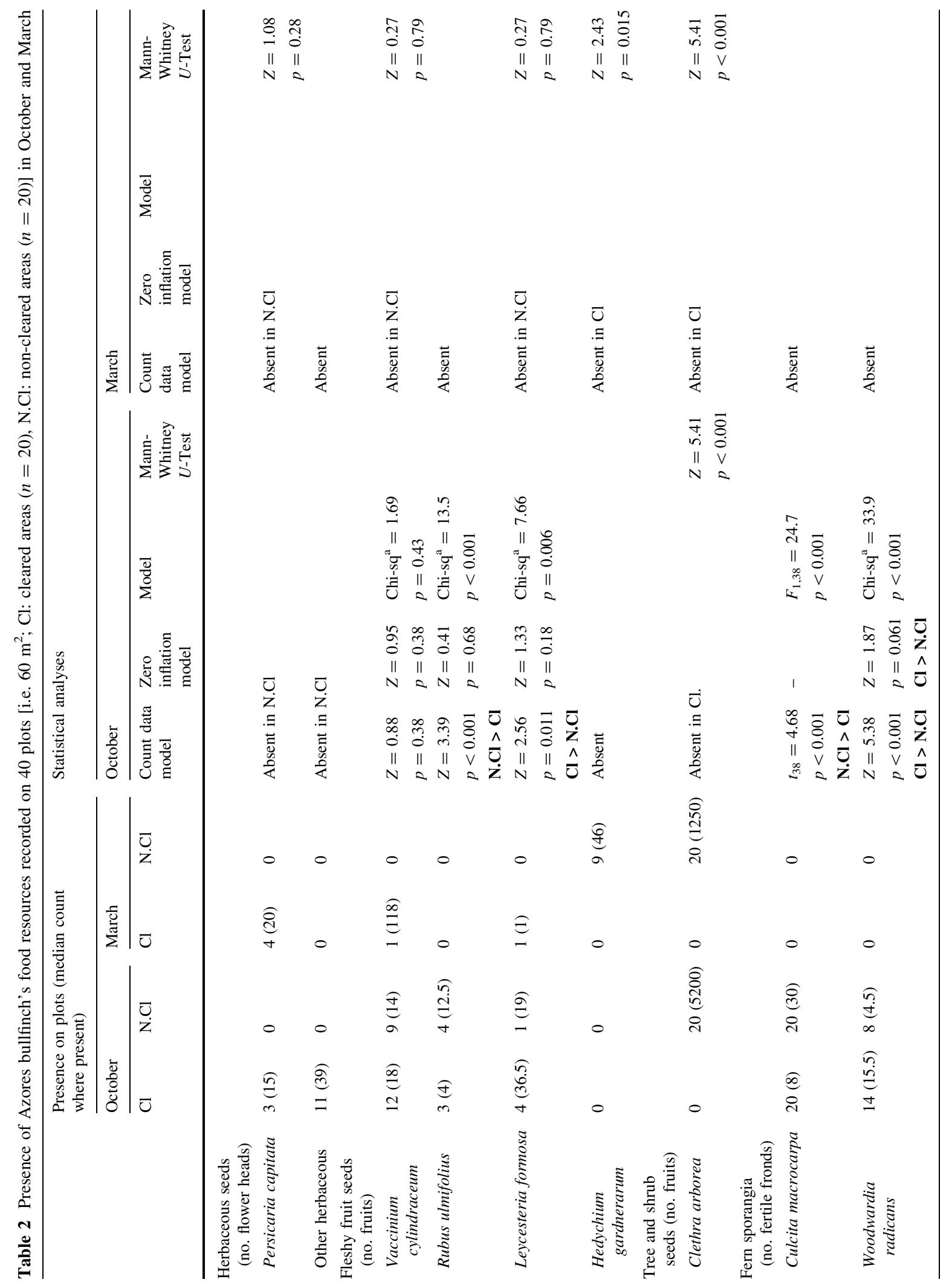



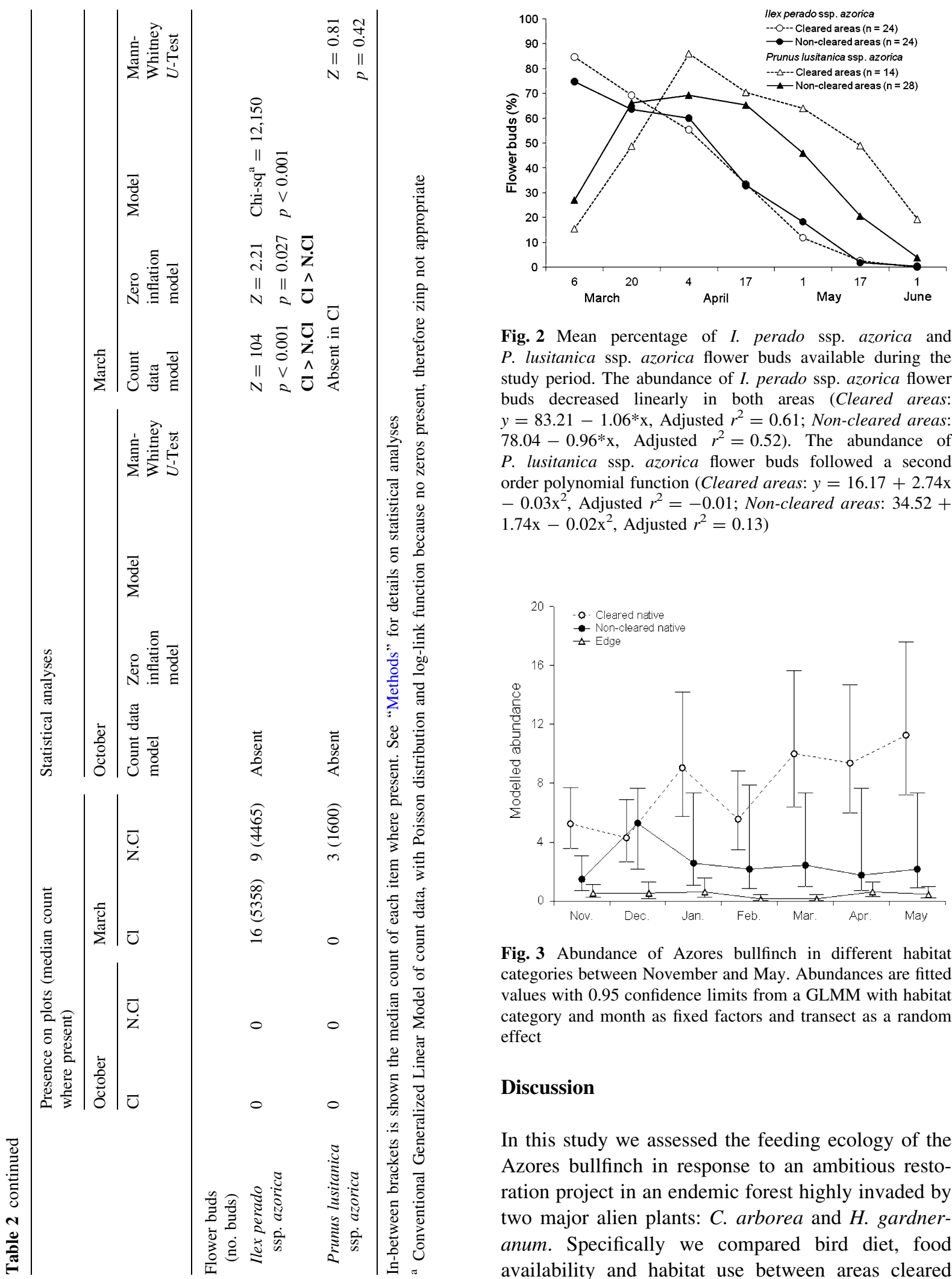

Fig. 2 Mean percentage of I. perado ssp. azorica and $P$. lusitanica ssp. azorica flower buds available during the study period. The abundance of $I$. perado ssp. azorica flower buds decreased linearly in both areas (Cleared areas: $y=83.21-1.06 * \mathrm{x}$, Adjusted $r^{2}=0.61 ;$ Non-cleared areas: $78.04-0.96^{*} \mathrm{x}$, Adjusted $r^{2}=0.52$ ). The abundance of $P$. lusitanica ssp. azorica flower buds followed a second order polynomial function (Cleared areas: $y=16.17+2.74 \mathrm{x}$ $-0.03 \mathrm{x}^{2}$, Adjusted $r^{2}=-0.01 ;$ Non-cleared areas: $34.52+$ $1.74 \mathrm{x}-0.02 \mathrm{x}^{2}$, Adjusted $r^{2}=0.13$ )

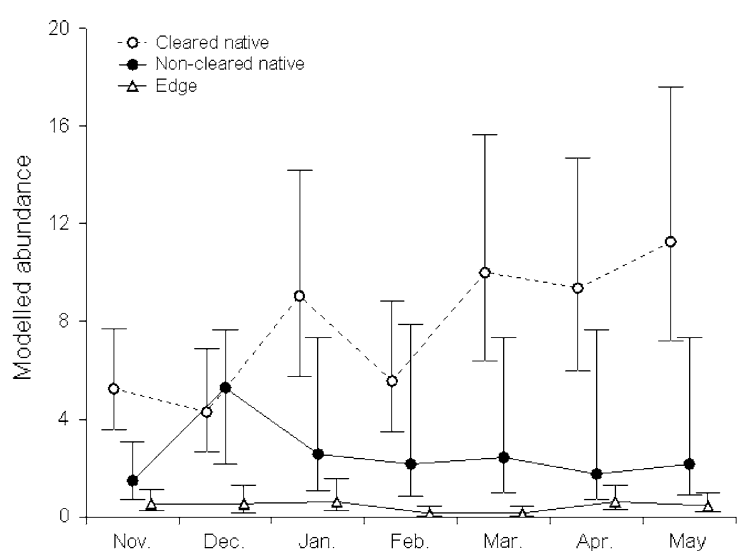

Fig. 3 Abundance of Azores bullfinch in different habitat categories between November and May. Abundances are fitted values with 0.95 confidence limits from a GLMM with habitat category and month as fixed factors and transect as a random effect

\section{Discussion}

In this study we assessed the feeding ecology of the Azores bullfinch in response to an ambitious restoration project in an endemic forest highly invaded by two major alien plants: C. arborea and H. gardneranum. Specifically we compared bird diet, food availability and habitat use between areas cleared 


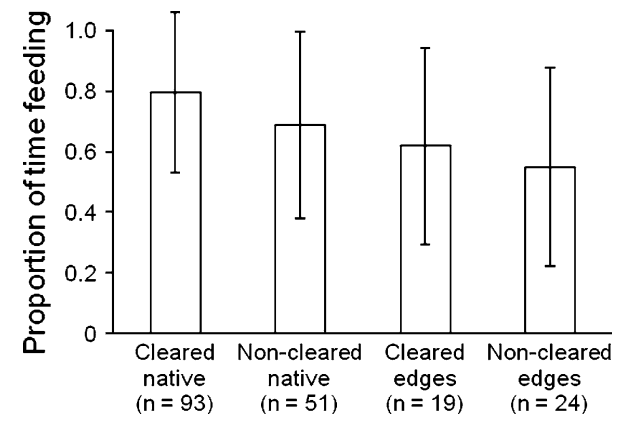

Fig. 4 Proportion of time allocated to feeding by the Azores bullfinch between November and May in each defined habitat category ( $n$ refers to the no. of birds recorded per habitat category). Vertical bars denote standard deviation

and not cleared of alien plants. Our data reveal an important short-term response of both the habitat and the Azores bullfinch to management, with significant implications for conservation.

Seeds of $C$. arborea, an extremely abundant resource in non-cleared areas throughout the winter, were entirely absent from cleared areas after management. There were also substantial increases in the availability of native food items following alien plant removal. Native shrubs and trees rapidly re-grew in cleared areas (Ceia and Silva 2008), which in turn negatively affected flowering/seeding of herbaceous plants.

These profound changes were strongly reflected in the diet and feeding behaviour of the Azores bullfinch. Winter diet differed fundamentally between cleared and non-cleared areas, since seeds of $C$. arborea, which formed the bulk of the winter diet in non-cleared areas, were replaced mainly by fern sporangia followed by flower buds in cleared areas. We recorded also for the first time the consumption of flower buds of $P$. lusitanica ssp. azorica (not recorded in the 1990s) which constitutes an important resource in March and April coinciding with the period they were more abundant. This information is extremely important, as the earlyspring consumption of flower buds of $P$. lusitanica ssp. azorica could be critical for the Azores bullfinch in managed laurel forest and therefore may be a critical factor in the restoration process. Our results seem to suggest that in a more natural laurel forest, $P$. lusitanica ssp. azorica might fill the temporal gap between the availability of fern sporangia and the flower buds of $I$. perado ssp. azorica.
Even though restoration activities will improve habitat in the long-term, it is important to understand the consequences of such a dramatic intervention in the habitat in the short-term. The key question for conservation managers is whether restoration activities created a severe short-term resource gap for wintering Azores bullfinches, or whether native food resources are adequate to fill that gap. These data indicate that, in general, cleared areas were at least as heavily used by Azores bullfinches as non-cleared areas, suggesting that even in the short-term the conservation management has not reduced habitat quality for foraging birds. Azores bullfinch density was similar in cleared and non-cleared areas throughout most of the autumn and winter. Furthermore, during spring Azores bullfinches seem to strongly prefer cleared areas over non-cleared areas. Azores bullfinches in the cleared areas actually spent more time in feeding activities than those in non-cleared areas refuting the hypothesis that birds would move into non-cleared areas to feed on $C$. arborea. Conversely, the observed pattern may result from the abundance of easily available and profitable seeds of $C$. arborea in non-cleared areas, leaving more time available for other behaviours. Nevertheless, it is clear that Azores bullfinches were not solely occupying cleared areas for the purposes of maintenance activities, but actively chose to forage in them. The proximity of cleared and non-cleared areas, and the considerable mobility of Azores bullfinches relative to the scale of the cleared and non-cleared habitat patches (confirmed from sightings of colour-ringed birds) means that the population could certainly have moved largely into non-cleared areas had this been the only adequate habitat during winter. The marked increase and improved flowering/seeding of several native plants within $12-18$ months after the removal of the invasive plants may explain the apparently successful use of native food sources in cleared areas. Most notably, buds of I. perado ssp. azorica, a native tree, were much more abundant (albeit highly patchy) in cleared areas during spring, where it formed the majority of the available food items, but not in the non-cleared areas. The one exception to this pattern was that in December, Azores bullfinches were more common in non-cleared areas than in cleared areas. Could this represent a short period when native plants do not yet meet the shortfall in $C$. arborea seeds? December diets were very limited in both habitat 
types; being composed almost entirely of fern sporangia in cleared areas, and C. arborea seeds in non-cleared areas. Fruits and buds of native shrubs/ trees and herbaceous seeds were not widely available, as fruit production appears to finish by December (Ramos 1995) and flower buds appear only in late January (this study). Fern sporangia are very rich in lipids (Rozenstvet et al. 2001; Arosa 2008) and may constitute an alternative food source when seeds are not available (Ramos 1995). However, experiments with captive birds suggested that, in December, Azores bullfinches prefer C. arborea seeds to fern sporangia (Ramos 1996b), meaning that some seeds may be necessary to complement the diet. Fern sporangia may also assume an important role in early-spring as data on the European bullfinch show that it cannot maintain its weight solely on flower buds (Newton 1967). However, the preference for non-cleared areas in December is not all pervasive, and a considerable proportion of the population did use cleared areas in the first winter after management. This result in the first year after restoration, when native vegetation had little time to recover, is encouraging, and it seems unlikely that the shortterm impact of restoration can jeopardize the longterm benefits from the recovery of native vegetation (Heleno et al. 2010). More importantly, and accounting with reinvasion of cleared areas, the rate of removal of invasive vegetation is in the order of a few tens of hectares per year, and the rate of native forest recovery is apparently fast relative to this time-scale (Heleno et al. 2010). Therefore, by the time $C$. arborea is becoming very scarce in the area, significant parts of the native forest will have been restored for several years, and will likely be providing more food resources into the December period. At low altitudes fern spores mature and are released earlier than at high altitudes (Arosa 2008), therefore, in a more mature forest, extending from low to high altitudes, fern sporangia and flower buds will be available for longer (Arosa et al. 2009a). This indicates the necessity of restoring areas of native laurel forest at lower altitudes in order to increase seeding periods of native plants (Ramos 1995; Ceia et al. 2009; Heleno et al. 2009). Also, after several years of restoration, fleshy fruit production might have increased sufficiently that fruit availability continues through into mid-winter.
Prior to the ongoing restoration actions, there were virtually no native laurel forest areas within the Azores bullfinch range that were free from C. arborea. Our results suggest that W. radicans, C. macrocarpa, I. perado ssp. azorica and $P$. lusitanica ssp. azorica were probably the original winter food resources consumed by the Azores bullfinch before the invasion of $C$. arborea in the 1950s. The observations of Arosa et al. (2009b) suggest that a third fern species, Pteris incompleta, is also important. Therefore, management of these five species should be carefully considered in the restoration of very large areas. Nevertheless, the data do give enough cause for concern that careful monitoring of Azores bullfinch trends and ecology would be strongly advisable over the coming years.

Acknowledgments This work was part of the Azores bullfinch monitoring programme included in the project LIFE NAT/P/000013 "Recovery of Azores bullfinch's habitat in the Special Protection Area of Pico da Vara/Ribeira do Guilherme". We thank all the involved partners and the LIFE programme for financing this project.

\section{References}

Arosa ML (2008) Fern feeding ecology of the Azores bullfinch, Pyrrhula murina. MSc thesis. Universidade de Coimbra

Arosa ML, Quintanilla LG, Ramos JA, Ceia R, Sampaio H (2009a) Spore maturation and release of two evergreen Macaronesian ferns, Culcita macrocarpa and Woodwardia radicans, along an altitudinal gradient. Am Fern J 99:260-272

Arosa ML, Ramos JA, Valkenburg T, Ceia R, Laborda H, Quintanilla LG, Heleno R (2009b) Fern feeding ecology of the Azores bullfinch (Pyrrhula murina): the selection of fern species and the influence of nutricional composition in fern choice. Ardeola 56:71-84

BirdLife International (2008) Pyrrhula murina. In: IUCN (2008) 2008 Red list of threatened species. http://www. iucnredlist.org. Accessed 20 Feb 2010

Bowles ML, Whelan CJ (1994) Restoration of endangered species. Cambridge University Press, Cambridge

Butchart SHM, Stattersfield AJ, Collar NJ (2006) How many bird extinctions have we prevented? Oryx 40:266-278

Ceia R (2008) Monitorização da população de Priolo. Relatório da acção F6 do Projecto LIFE Priolo. SPEA, Lisboa

Ceia R, Silva C (2008) Esquemas de monitorização das acções de remoção de exóticas e de produção e plantação de espécies nativas. Relatório da acção F5 do Projecto LIFE Priolo. SPEA, Lisboa

Ceia R, Heleno R, Ramos JA (2009) Summer abundance and ecological distribution of passerines in native and exotic forests in São Miguel, Azores. Ardeola 56:25-39 
D'Antonio C, Meyerson LA (2002) Exotic plant species as problems and solutions in ecological restoration: A synthesis. Restor Ecol 10:703-713

Dobson AP, Bradshaw AD, Baker AJM (1997) Hopes for the future: restoration ecology and conservation biology. Science 277:515-522

Forup ML, Henson KSE, Craze PG, Memmott J (2008) The restoration of ecological interactions: plant-pollinator networks on ancient and restored heathlands. J Appl Ecol 45:742-752

Genovesi P (2005) Eradications of invasive alien species in Europe: a review. Biol Invasions 7:127-133

Gil A (2005) Plano de gestão da Zona de Protecção Especial Pico da Vara/Ribeira do Guilherme. SPEA, Lisboa

Heleno RH, Ceia RS, Ramos JA, Memmott J (2009) The effect of alien plants on insect abundance and biomass: a food web approach. Conserv Biol 23:410-419

Heleno RH, Lacerda I, Ramos JA, Memmott J (2010). Evaluation of restoration effectiveness: community response to the removal of alien plants. Ecol Appl. doi: 10.1890/09-1384

Kremen C, Hall G (2005) Managing ecosystem services: what do we need to know about their ecology? Ecol Lett 8:468479

Monticelli D, Ceia R, Heleno R, Laborda H, Timóteo S, Jareño D, Hilton GM, Ramos JA (2010). High survival rate of a critically endangered species, the Azores Bullfinch Pyrrhula murina, as a contribution to population recovery. $\mathrm{J}$ Ornithol. doi: 10.1007/s10336-010-0501-4

Newton I (1964) Bud-eating by bullfinches in relation to the natural food supply. J Appl Ecol 1:265-279

Newton I (1967) The feeding ecology of the Bullfinch (Pyrrhula pyrrhula L.) in Southern England. J Anim Ecol 36:721-744

Newton I (1998) Population limitation in birds. Academic Press, London

R Development Core Team (2009) R: a language and environment for statistical computing. R Foundation for Statistical Computing, Vienna, Austria. http://www.R-project.org

Ramos JA (1994) Fern frond feeding by the Azores bullfinch. J Avian Biol 25:344-347

Ramos JA (1995) The diet of the Azores bullfinch Pyrrhula murina and floristic variation within its range. Biol Conserv 71:237-249

Ramos JA (1996a) Introduction of exotic tree species as a threat to the Azores bullfinch population. J Appl Ecol $33: 710-722$
Ramos JA (1996b) The influence of size, shape and phenolic content on the selection of winter foods by the Azores bullfinch. J Zool 238:415-433

Rodriguez LF (2006) Can invasive species facilitate native species? Evidence of how, when, and why these impacts occur. Biol Invasions 8:927-939

Rozenstvet OA, Sakasnov SV, Filin VR, Dembitsky VM (2001) Seasonal changes of lipid content in the leaves of some ferns. Physiol Plantarum 113:59-63

Schäffer H (2002) Flora of the Azores, A field guide. Margraf Verlag, Weikersheim

Silva L (2001) Plantas invasoras no Arquipélago dos Açores: caracterização geral e estudo de um caso, Clethra arborea Aiton (Clethraceae). PhD thesis. Universidade dos Açores, Ponta Delgada

Silva L, Smith CW (2004) A characterization of non-indigenous flora of the Azores Archipelago. Biol Invasions 6:193-204

Silva L, Pinto N, Press B, Rumsay F, Carine M, Henderson S, Sjogren VE (2005) List of vascular plants (Pterydophyta and Spermatopgyta). In: Borges PAV, Cunha R, Gabriel R, Martins AMF, Silva L, Vieira V (eds) A list of the terrestrial fauna (Mollusca and Arthropoda) and flora (Bryophyta, Pteridophyta and Spermatophyta) from the Azores. pp 131-155. Direcção Regional de Ambiente and Universidade dos Açores, Horta, Angra do Heroísmo and Ponta Delgada

StatSoft, Inc. (2004) STATISTICA (data analysis software system), version 7. http://www.statsoft.com

Van Riel P, Frias Martins AM, Beckeljau T (2000) Eradication of exotic species. Trends Ecol Evol 15:515

Vander Zanden MJ, Olden JD, Zedler JB (2006) Food-web approaches in restoration ecology. In: Falk DA, Palmer MA, Zedler L (eds) Foundations of restoration ecology. Island Press, USA, pp 165-189

Vitousek PM, D'Antonio CM, Loope LL, Rejmanek M, Westbrooks R (1997) Introduced species: a significant component of human-caused global change. $\mathrm{N}$ Z J Ecol 21:1-16

Young TP, Chase JM, Huddleston RT (2001) Community succession and assembly. Ecol Restor 19:5-18 